\title{
Jugaad Trocar for a 5-mm Laparoscopic Cannula
}

\author{
Ramakrishna $\mathrm{HK}^{1}$ (D) $\cdot$ Swarnalatha $\mathrm{MC}^{2}$
}

Received: 19 November 2020 / Accepted: 27 November 2020 / Published online: 8 January 2021

(C) Association of Surgeons of India 2021

\begin{abstract}
When we are practicing, especially in rural India, we often face problems of instrument failure or lost instrument, etc... which may sometimes necessitate abandoning the procedure just because of the lack of a single instrument. We do mobile laparoscopic surgery, carrying all the laparoscopic instruments to far-off places, as far as $60-80 \mathrm{~km}$. On one such occasion, my staff had lost a 5 -mm trocar, which had gone unnoticed until I posted a case for laparoscopic cholecystectomy. There was not much time to buy a new one and also it was difficult to procure from the dealer because of the COVID-19 situation. Just because of the lack of one instrument we were facing a situation of postponing laparoscopy!
\end{abstract}

Keywords Innovation $\cdot$ Laparoscopic trocar $\cdot 5$-mm cannula $\cdot$ Rural surgery $\cdot$ Resource constraints $\cdot$ Jugaad

\section{Material}

As they say, necessity is the mother of invention. We thought of using some alternative instrument to the trocar. We regularly use a Romovac suction drain for prevention of seroma in incisional hernioplasty. A used needle rod of the Romovac came in handy. Since it isslightly bent at the sharp end, we had to hammer it mildly to straighten it. Then we went to a local welding shop and explainedhim what we wanted. He cut the rod to an appropriate length and welded a stainless steel washer to the end of the rod. Also he shaped the sharp end to the triangular shape of a regular laparoscopic trocar. The trocar was ready with a cost of about INR 100 within half a day!

The combination of images shown in Fig. 1 explains it all.

\section{Compliance with Ethical Standards}

Conflict of Interest The authors declare that they have no competing interests.

Publisher's Note Springer Nature remains neutral with regard to jurisdictional claims in published maps and institutional affiliations.

Ramakrishna HK

rksrivathsa@hotmail.com

1 Lakshmi Nursing Home, New Bridge Road, Bhadravathi, Karnataka 577301, India

2 Bhadravathi, India 
Fig. 1 Combination of images explaining the design
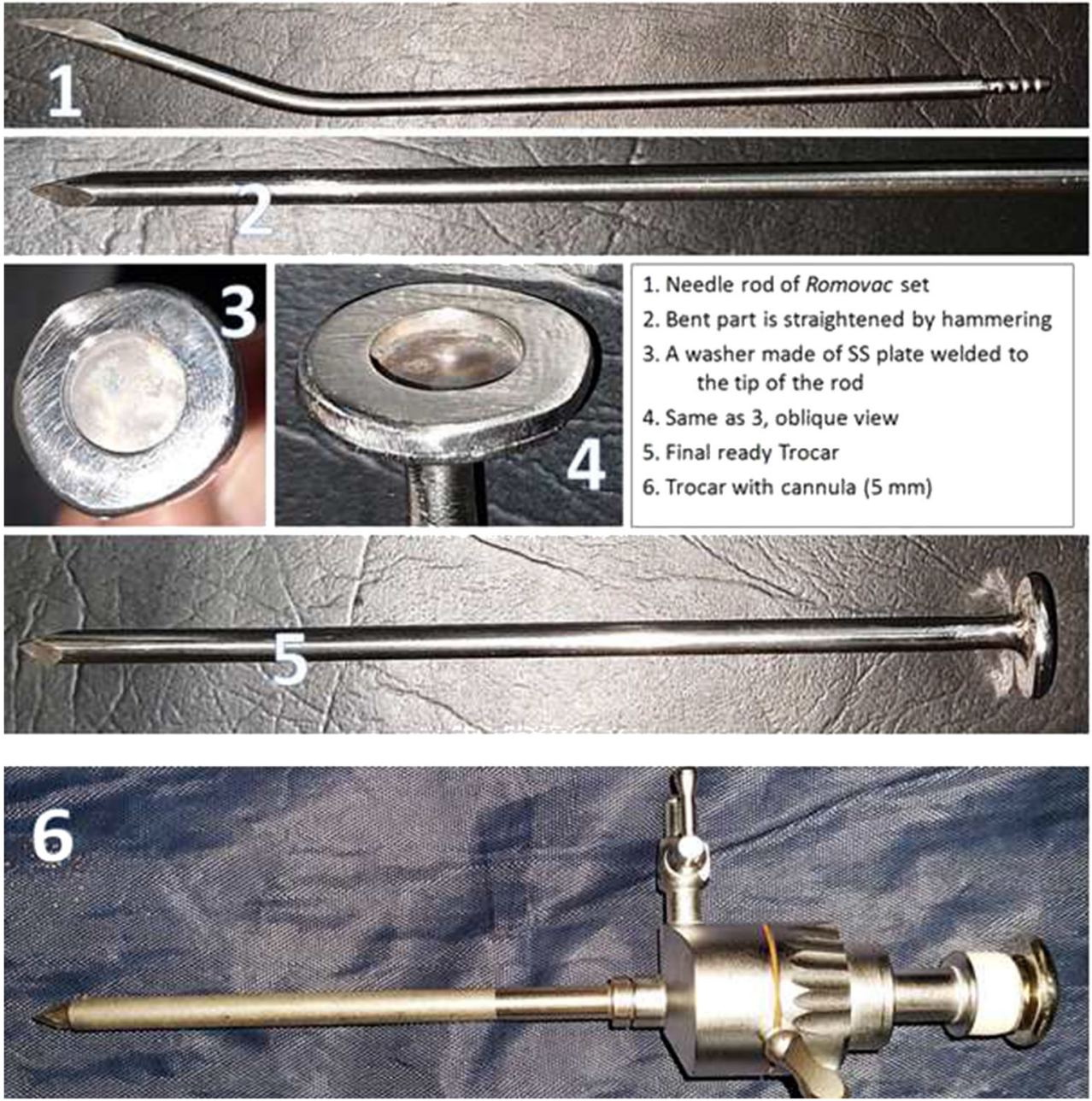